\title{
Os Passos Criativos e Artísticos do Diretor Giorgio Strehler na Constituição de suas Encenações
}

\section{*Camila Paula Camilotti}

\begin{abstract}
Resumo
Na constituição de montagens teatrais a criatividade do diretor de teatro Giorgio Strehler se expressava sobremaneira. Cada passo criativo e intelectual do diretor no percurso preparatório de suas encenações era permeado por reflexões, estudos e, sobretudo, inspiração. A preparação de seus espetáculos era sinônimo de pesquisa profunda: em primeiro lugar, acerca do texto dramático e suas implicações e, em segundo, acerca da própria encenação e de seus elementos constitutivos. Com base nesses pressupostos, o objetivo deste trabalho reside em observar os passos criativos e artísticos do diretor italiano Giorgio Strehler na constituição de suas montagens teatrais, desde a preparação dos elementos cênicos, até a preparação dos atores na constituição de seus papeis. A conclusão que se obteve com esse estudo foi que a exigência e o envolvimento de Strehler na preparação das montagens teatrais o conduzia, quase sempre, a resultados satisfatórios e, como conseqüência, suas encenações se enquadram em uma esfera artística de alta qualidade estética e cultural.
\end{abstract}

Palavras-chave: Giorgio Strehler - passos criativos - constituição de encenação

\begin{abstract}
In the process of constitution of theatrical productions, Giorgio Strehler's creativity was expressed greatly. Each step of his creative and intellectual process in the preparation of a miseen-scéne was surrounded by reflexion, study, and, specially, inspiration. The preparation of his spectacles was a synonym of a deep research: Firstly on the dramatic text and its implications and, secondly, on the mise-en-scéne itself and its elements. From this perspective, this work aims at observing the creative and artistic process of the Italian director Giorgio Strehler in the constitution of his theatrical productions - from the constitution of scenic elements to the preparation of actors in the construction of their roles. The study of Giorgio Strehler's creative and artistic process led to the following conclusion: the director's demand and exhaustive involvement in the preparation of his stage productions led, almost always, to satisfactory results and, as a consequence, his theatrical productions are considered to be of a high aesthetic and cultural quality.

keywords: Giorgio Strehler - creative steps constitution of a mise-en-scéne
\end{abstract}


A Giorgio Strehler, nascido na cidade de Barcola, em Trieste, em 14 de agosto de 1921, foi um diretor que se destacou na dramaturgia contemporânea italiana pela sua forma critica, reflexiva e criativa de lidar com a constituição e execução de suas encenações. Além de artista, Strehler foi igualmente um grande intelectual. Um homem que se preocupava com questões políticas, sociais e artísticas do país e que concebia o teatro como um instrumento de reflexão e de ensinamento que estava além do divertimento. Com seu colega Paolo Grassi, em 1947, fundou o Piccolo Teatro de Milão, ativo até os dias de hoje e com três sedes: Piccolo Teatro Grassi (sede histórica), Piccolo Teatro Strehler e Piccolo Teatro Studio. Por incrível que pareça, somente após a fundação do Piccolo, a dramaturgia italiana passa a ter, pela primeira vez, um local público, com estrutura adequada para sediar seus espetáculos. Por essa razão, o Piccolo Teatro foi considerado o primeiro teatro estável da Itália. Com efeito, ao fundar o Piccolo, o diretor italiano, de certa forma, contribuiu sobremaneira com a dramaturgia em seu país e seu modo particular de lidar com as encenações, como se vera a seguir, podem servir de inspiração para futuros diretores e/atores que, assim como Strehler, consideram o teatro um canal transmissor de reflexões e ensinamentos, alem do entretenimento.

Stella Casiraghi (2000), na introdução à coletânea das cartas de Strehler, afirmou: "um homem de teatro, por sua natureza, não pode, não deve e não sabe se explicar. E de Strehler, homem de teatro puríssimo, não podemos esperar comunicação linear, conexa, fechada ${ }^{1}$ " (p. 9). Evidências dessa comunicação "não linear" do diretor encontram-se nas cartas que trocava com suas equipes. Nelas, Strehler "divagava". Suas ideias criativas "proliferavam" em seu inconsciente como células, e ele viajava nesse mundo criativo aleatoriamente, sem conseguir seguir linearidade. E quando se tratava de explicar o "como" e os "porquês" de seu mestiere artístico, não conseguia fazê-lo.

Em depoimento, o diretor revela ter algumas "ideias fundamentais" acerca de uma encenação e que sua materialização acontecia no encontro com os atores e com os técnicos. Somente com eles, que auxiliavam Strehler no processo de verbalização das ideias, é que o diretor conseguia "enxergar" concretamente o que queria fazer no palco. Segundo Strehler (1997), "Descobre-se uma estrada, sabe-se que ela deve terminar lá, mas através de quais estradas secundárias chegar, bom, isso é algo a ser descoberto. ${ }^{2 ”}$ (p. 11)

O trabalho acontecia, as ideias se faziam presentes nas suas interpretações textual e cênica das obras, mas de modo quase "inconsciente", sem deixar espaço para a lógica e para os porquês. Sua vasta criatividade unia-se ao seu conhecimento crítico do mundo e do teatro, deixando-o, por vezes, angustiado, pois não conseguia administrar o turbilhão de ideias, sensações e pensamentos que o acometiam. O grande dilema que Strehler, como artista, sentia, vivenciava e expressava com angústia em suas cartas era o de perceber, perante a complexidade e o excesso de sua sensibilidade criativa, o limite dos signos que tinha disponíveis para expressar sua inventividade. Faltava-lhe medida, regra ou ordem que, de alguma forma, sistematizasse todo esse magma criativo sem tirar sua excepcionalidade. $\mathrm{O}$ emaranhado de ideias e sensações que permeavam o universo criativo do diretor o inquietava, mas era o combustível que o conduzia aos resultados do palco. Junto às suas equipes, "embarcava" na busca de soluções (e inspirações) para suas encenações.

Em seu percurso criativo e artístico, Strehler procurava lidar com os "mistérios" do teatro por meio de estudo e de reflexão. O texto dramático se tornava, para ele, território de constantes indagações e o palco, o lugar de experimentação e de possíveis respostas. O diretor tinha um modo particular de preparar e conduzir um espetáculo. Trabalhava com voracidade, com paixão. Ao se referir ao trabalho de Strehler, o diretor americano Robert Wilson em prefácio ao livro Strehler dirige, revelou (1997):

A primeira direção de Strehler que vi foi Le nozze di Figaro' em Paris' E nunca' em trinta anos de trabalho teatral' me ocorreu de ver alguém como ele que tivesse um senso tão pessoal da cena' que tivesse um estilo próprio' um modo seu de fazer as coisas' um léxico próprio para cada aspecto da cena: o comportamento dos atores' os figurinos' as luzes' a cenografia' a dramaturgia: um senso completo do teatro. ${ }^{3}$ (p. 11)

\footnotetext{
Esse “método” não era dotado de uma linearidade absoluta e sistemática, ou, como diria o próprio

L'uomo di teatro, per sua natura, non può, non deve e non sa spiegarsi. E da Strehler, uomo di teatro purissimo, non ci si poteva aspettare una comunicazione lineare, netta, chiusa.

Allora si scopre una strada, si sa che deve finire là, ma attraverso quali strade secondarie arrivarci, beh, questo è tutto da scoprire.

3 La prima regia di Strehler che vidi fu quella per Le nozze di Figaro a Parigi. E raramente, in trent'anni di lavoro teatrale, mi è capitato di vedere qualcuno che come lui avesse un senso così personale della scena, che avesse una sua sigla, un suo modo di fare le cose, un suo lessico, per ogni aspetto della scena: il comportamento degli attori, i costumi, le luci, la scenografia, la drammaturgia: un senso completo del teatro.
} 
Strehler, de uma "metodologia" (1997, p. 25), mas era feito com seriedade singular e com envolvimento profundo em todos os âmbitos do espetáculo (texto, cenário, luzes, som, figurinos).

O passo inicial no percurso de preparação estava na leitura, no estudo e na interpretação do texto dramático. O texto, para o diretor, era o "sopro da vida" do espetáculo e, portanto, devia ser bem compreendido no âmbito crítico, contextualizado para o público receptor, coerente com os aspectos visuais do espetáculo e bem enunciado pelos atores no palco. Assim, o diretor italiano procurava estudá-lo de modo exaustivo, construindo a partir dele as mais profundas interpretações.

Ao ser questionado sobre seu método de estudo textual, Strehler respondeu (1997): "Parto de uma ótica fundamental de não conhecer absolutamente nada. De não saber. Que é a coisa mais difícil de se conseguir, com tanta bagagem cultural que temos, com todas as nossas paixões, nossas leituras e nossos gostos. ${ }^{4}$ " (p. 28) $\mathrm{E}$, a partir dessa perspectiva livre de condicionamentos, questionava, indagava, refletia sobre o texto e suas possíveis conexões com a realidade que o cercava. Assim, começava a estabelecer relações com os elementos visuais que posteriormente fariam parte do seu espetáculo.

A análise do texto dramático conduzia Strehler ao segundo passo de seu processo artístico e criativo, ou seja, a construção dos elementos cênicos: luz, som, cenário, e figurinos. Nesse âmbito da encenação, o diretor mostrava-se extremamente exigente e buscava realizar um espetáculo perfeito sob o ponto de vista técnico, pois tinha plena consciência de que o sucesso da montagem dependia diretamente do bom funcionamento dos aparatos técnicos. O cenário era, para o diretor, o lugar essencial, o ponto de partida para a ação, pois nele os atores se movimentam, falam, agem, vivem. Era, segundo Strehler (1997) "a parte decisiva e fundamental da mise-en-scène." (p. 57)

Assim, levando em consideração esse ponto de vista, Strehler mergulhava, junto ao cenógrafo, na preparação cenográfica dos seus espetáculos. O primeiro passo do diretor consistia em unir-se à sua equipe técnica e colocar-se diante do texto para construir a partir dele a "atmosfera" ideal para sua encenação. Era o momento propício para se pensar nos detalhes que fariam parte do "universo cênico" de um texto, transformando em cores, luzes e sons, as linhas do código verbal. Era o momento de "converter o texto em um poderoso fato de comunicação estética, emotiva e intelectual. 5“" (STREHLER, 1997, p. 58)

O modo com o qual Strehler lidava com essa fase era sempre abstrato. Conforme mencionado anteriormente, o diretor, muitas vezes, não conseguia lidar com a imensidão de ideias que permeavam seu universo criativo. Assim, "explicava-se” aos cenógrafos intuitivamente, por meio de sensações e não de imagens concretas. Ezio Frigerio, cenógrafo que trabalhou junto a Strehler na construção de vários espetáculos ${ }^{6}$ revela, em depoimento, o percurso criativo e artístico de Strehler nessa primeira fase de construção cênica (1997):

\begin{abstract}
Inicialmente, Strehler tem uma intuição' imagina o espetáculo que quer Mas não procede por imagens precisas' e sim por sensações. Ele não diz, "quero aquela coisa" -- e quando o diz, "aquela coisa" depois geralmente não é exatamente o que ele quer Ao contrário' diz, "sinto" esta atmosfera' gostaria de fazer um espetáculo deste tipo' queria contar este tipo de história: um espetáculo muito teatral' ou um espetáculo muito realista Frequentemente essas suas sensações são intercaladas de lembranças da infância [‥]. Suas sensações são sempre repletas de intuições muito profundas e penetrantes -exatamente como uma flecha que atinge o coração de quem as sente ${ }^{7}$ (p. 61)
\end{abstract}

Os resultados atingidos nesse primeiro passo conduziam, pouco a pouco, à construção concreta do espaço cênico. As ideias "sentidas” por Strehler tornavam-se palpáveis à medida que eram expressas no papel, por meio dos desenhos, que ele chamava de "rascunhos". Esse material sofria modificações ao longo do seu percurso de construção; logo, não havia somente uma versão de cada "rascunho", mas várias até que chegassem ao estágio "final". O diretor reconhecia nisso a natureza mutável do teatro: espaço das probabilidades, no qual

\footnotetext{
$4 \quad$ Mi muovo sempre nell'ottica fondamentale di non conoscere assolutamente niente. Di non sapere. Che è la cosa più difficile da ottenere, col sedimento culturale che abbiamo, con tutte le nostre passioni, le nostre letture, i nostri gusti, ecc.

[...] trasformare quel testo in un potente fatto di comunicazione estetica, emotiva e intellettuale.

L'angelo di fuoco (1955-56), Il matrimonio segreto (1955-56),L'opera da tre soldi (1955-56), Arlecchino servitore di due padroni (1955-56), I giganti della motagna (1966-67) e Simon Boccanegra (1971-72).

7 Inizialmente Strehler ha un'intuizione, immagina lo spettacolo che vuole. Ma non procede per immagini precise, bensì sempre per sensazioni. Lui non dice, voglio quella tal cosa - e molto spesso quando dice così poi non è la cosa che vuole realmente - dice piuttosto, io sento quest'atmosfera, vorrei fare uno spettacolo di questo tipo, vorrei raccontare questo tipo di storia: uno spettacolo molto teatrale, o uno spettacolo molto realista. Molto spesso queste sue sensazioni sono inframmezzate da ricordi d'infanzia. [...] Le sensazioni sono sempre delle intuizioni molto profonde, acutissime - veramente come una freccia che colpisca il cuore di chi le sente.
} 
tudo se encontra em constante processo de evolução. Cada ensaio, cada discussão, cada reflexão abria as portas para novas modificações no percurso de construção do cenário.

Quando a cenografia estava a caminho de se concretizar, ou seja, estava saindo do papel para viver no palco, com todos seus elementos físicos, vivos e concretos, novas modificações eram feitas. Tratava-se, portanto, do momento mais difícil para os cenógrafos, pois Strehler poderia aprovar a construção, como desaprová-la radicalmente e exigir de sua equipe grandes mudanças. Segundo Walter Pagliaro, assistente de direção, que começou a trabalhar com Strehler em 1979, o diretor, em suas modificações, procurava reduzir a cenografia ao seu essencial (1997, p.70): "Fazem-se mudanças drásticas no sentido de essencializar, isso sim: algo que era uma grande sala construída aos poucos era 'despida' durante os ensaios até se tornar, não sei, uma luz. E acredito que são modificações essenciais. ${ }^{8}$ ” (p. 70)

Essa rigorosa exigência de Strehler na aprovação do cenário não envolvia somente os cenógrafos e diretores de cena, mas também a toda a equipe artística, que deveria "se adaptar" às modificações (muitas vezes, radicais). Em depoimento, Strehler revela que a aprovação do cenário só acontecia com a movimentação dos atores no palco, no momento do ensaio. Ali, ao vê-los vestidos com seus figurinos pré-definidos, o diretor conseguia ter uma visão mais concreta do espetáculo em sua totalidade. Metaforicamente, era como se a equipe técnica iniciasse a "procissão" e, em determinado ponto da estrada, pedisse a "ajuda" dos atores para inserirse nela e complementá-la. Segundo Strehler, por ser tão envolvente, tratava-se de um trabalho de pesquisa, "quase arqueológico" (1997, p.68), em busca do espaço cênico ideal e ligado harmoniosamente aos outros elementos da encenação.

Quando o cenário já se encontrava a caminho de sua edificação, Strehler passava a se preocupar com o figurino. Tratava-se de mais um momento importante de interação Strehler - equipe técnica. Na verdade, o trabalho do figurino acontecia quase simultaneamente ao desenvolvimento do trabalho da cenografia. Tanto que, na maioria das vezes, o cenógrafo é, também, o figurinista; a razão disso é simples: impossível não pensar no cenário sem levar em consideração os figurinos que os atores utilizarão em cena. A interação entre esses dois elementos é crucial para o sucesso do espetáculo. A figurinista Luisa Spinatelli (1997), que trabalhou com Strehler em diversos espetáculos ${ }^{9}$, explica o porquê: "Diretor, figurinista e cenógrafo devem discutir juntos. Se não viajam juntos, os resultados não acontecem. [...] o figurino por si só não existe se você não conhece que impacto, que pano de fundo, que luz, que atmosfera deve ter ${ }^{10 “ . ~(p . ~ 73) ~}$

O processo de construção do figurino por Strehler seguia, portanto, o mesmo nível de exigência da preparação do texto e do cenário: por meio da exposição das ideias do diretor, que eram feitas sempre de modo pictórico e abstrato, o figurinista começava a desenvolver os desenhos. Uma vez aprovados por Strehler, os modelos iniciavam o seu caminho para concretização: eram transferidos para o departamento da alfaiataria do teatro e, quando confeccionados, eram finalmente entregues aos atores para o momento das provas. Entretanto é valido lembrar que a transição de um passo a outro do processo era minuciosa e cuidadosa, o que consequentemente exigia um tempo de preparação consideravelmente vasto.

O input visual de Strehler no que dizia respeito aos figurinos acontecia a partir de imagens precisas e casuais, que faziam parte do quotidiano: pessoas nas ruas, imagens em revistas, jornais e livros. A partir daí, o diretor começava a criar, em seu universo interpretativo, as próprias imagens, cores, tecidos que pudessem expressar (ou até revelar) as características dos personagens, em determinado tempo e espaço.

Quando se tratava de uma obra a ser encenada em determinada época histórica, por exemplo, o diretor fazia uma pesquisa exaustiva dos figurinos através das artes plásticas, sobretudo da pintura, a qual se revelava poderoso instrumento de inspiração. Além de fornecer um mundo pictórico rico, mostrava um figurino e proporcionava atmosferas, luzes e cores. Era como se a pintura fosse o "modelo" pronto para a cena.

Uma vez aprovados por Strehler, os "modelos" desenhados nos rascunhos entravam em processo de realização. Spinatelli (1997) explica que essa fase era uma das mais desafiadoras do processo, pois era repleta de adversidades, por vezes difíceis de serem solucionadas:

Por exemplo' se encontramos um tecido de qualidade' mas com a cor errada' devemos preparar a tinta para pintálo' ou' se é muito escuro' precisamos clareálo. Temos que fazer uma preparação de base'

\footnotetext{
8 Cambiamenti drastici si fanno nel senso di essenzializzare, questo sì: qualcosa che magari era un grande salone costruito pian piano si è spogliato durante le prove fino a diventare, non so, una luce. E credo che siano modifiche essenziali.

L'anima buona di sezuan (1980, 1995); Atto senza parole fra giorni felici (1981-82), La grande magia (1985-85), Elvira o la passione teatrale (1985-86), Faust frammenti parte I e II (1988-89, 1990-91), Libero (1988-89), L'isola degli schiavi (1994-95).

10 Regista, costumista e scenografo devono parlare tutti e tre. Se non viaggiano tutti e tre insieme, i risultati non vengono fuori. [...] il costume in sé non esiste se non sai che impatto, che sfondo, che luce, che atmosfera deve avere.
} 
antes do recorte. Isso se torna uma técnica de costura: como fazer para traduzir um tipo de forma' de silhouette' de personalidade para certo tipo de tecido' certo tipo de corte' certo tipo de vestimenta. Não é questão de originalidade' mas de seriedade ao enfrentar o problema ${ }^{11} \cdot(p .75)$

Além disso, acrescenta a figurinista, havia as dificuldades de lidar com a confecção dos figurinos históricos, pois a estrutura física de um ator de determinada época no passado não é a mesma de um ator contemporâneo. Enfim, não se tratava somente de confeccionar os figurinos de acordo com as medidas dos atores, mas dar a eles uma característica natural, sem parecer "forçados" ou "improvisados". E Strehler tinha "olho clínico" para os mínimos detalhes dos figurinos: se não estivessem de acordo com suas intenções, eram modificados radicalmente ou, nos casos mais extremos, refeitos.

Antes da confecção definitiva dos figurinos, Strehler exigia a utilização dos provisórios ou "figurinos de prova”, que eram semelhantes aos definitivos. Com eles, que eram sempre analisados sob a luz, Strehler poderia ainda modificar algo que não estivesse de acordo com seu protocolo de intenções. A luz servia como termômetro para "medir" as cores, pois, através dela, o diretor conseguia ter percepção mais concreta e concluir se aquele figurino, com aquela determinada cor, ajustava-se ao ambiente total do espetáculo.

Gerardo Modica (1997), colaborador de luz que em 1970 passou a trabalhar integralmente no Piccolo Teatro, informa que, "quando chega o figurino ele [Strehler] fica alí e se diverte: a manga mais curta, a perna da calça é muito longa, tenta levantar o colete, prova a jaqueta assim, etc ${ }^{12}$ “ (p. 78). Porém, conforme adverte Frigerio (1997, p.79), havia risco nesse momento de provas: "Strehler se apaixona tão perdidamente pelos figurinos provisórios a ponto de preferir usá-los como definitivos. Um perigo ${ }^{13}$. “

Após a avaliação dos figurinos provisórios, passava-se para sua confecção definitiva, para que, finalmente, eles pudessem ser entregues aos atores. No momento da entrega, Strehler exigia uma prova à moda alemã: os atores entravam individualmente no palco. Strehler observava seus figurinos sob a luz definitiva, no cenário definitivo. Em seguida, exigia a presença de todos os atores juntos, um ao lado do outro, no intuito de observá-los em confronto com todo o ambiente cênico já construído.

Outra marca do diretor em relação aos figurinos estava na sua predileção pelos já usados. Para Strehler, eles representavam algo com passado, com história, com vida. Sua reutilização era sinônimo de recriação, de transformação, enfim, de renovação. Quando se tratava de um espetáculo contemporâneo, a reutilização dos figurinos era feita quase de modo automático, pois eles já existiam de outros espetáculos. Porém, quando se tratava de espetáculos de época, a reutilização raramente acontecia, pois era necessário confeccioná-los pela primeira vez.

Na sequência dos elementos constitutivos do espetáculo, encontram-se as luzes, que eram preparadas e projetadas pelo próprio Strehler. Para o diretor, esse elemento era de uma importância cênica extrema, pois, como antes mencionado, servia, em primeiro lugar, como termômetro para medir e analisar os figurinos e o cenário; em segundo lugar, como "canal de expressão artística" para os atores, e em terceiro lugar, como gerador de atmosferas. No primeiro caso, Strehler só aprovava o cenário e os figurinos após colocá-los em confronto com a luz -- o que representava um desafio para a equipe técnica, visto que a tonalidade das cores e o brilho poderiam variar definitivamente sob a ótica das luzes.

No segundo caso, o diretor utilizava luzes para criar uma atmosfera capaz de explorar e incentivar a criatividade dos atores -- ele acreditava que, proporcionando-lhes determinado "ambiente", seriam capazes de expressar-se artística e criativamente com mais facilidade e mais naturalidade. No terceiro caso, a função das luzes era a de gerar as diferentes atmosferas ao longo da trama da encenação (dia/noite, verão/inverno, sol/ lua) e, consequentemente, despertar as mais diversas emoções no público.

Para criar todos esses efeitos, a luz deveria ser projetada com técnicas precisas de ritmo, espaço de tempo e velocidade. Obviamente, Strehler era imensamente cauteloso nesse aspecto e exigia de seus assistentes técnicos exatidão, para que não houvesse erros na projeção das luzes e para que os efeitos desejados fossem alcançados. Trabalhar com Strehler nesse âmbito era sinônimo de viver em constante tensão física e emocional: um pequeno equívoco era capaz de "levar o diretor à loucura".

\footnotetext{
11 Per esempio, trovi una stoffa che va bene di qualità però non giusta di colore, allora le devi preparare una tinta; oppure è troppo scura, e allora la devi stingere. Devi fare la preparazione di base, prima del taglio. Diventa un fatto di tecnica sartoriale: come fare a tradurre questo tipo di forma, di silhouette, di carattere, in stoffa di un certo tipo, taglio di un certo tipo, e vestibilità di un certo tipo. Non è una questione di originalità, ma di serietà nell'affrontare dei problemi.

12 Quando arriva il costume, lui si mette lì e ci gioca su: la manica più corta, la gamba è troppo lunga, prova ad alzare il colletto, prova la giacca così, ecc.

13 [...] Strehler si affeziona talmente che al momento che arrivano le cose vere lui vuole quelle di prova. È un pericolo.
} 
Quanto à estética das luzes, Strehler optava -- como nos figurinos e no cenário -- por cores neutras ou claras, a fim de construir ambientes delicados, tênues. As cores fortes eram utilizadas somente em casos excepcionais, em que se faziam extremamente necessárias. O técnico da luz, Adriano Todeschini (1997), conta que em Fausto, Strehler interpretou a cena da "cozinha da bruxa" como uma danceteria moderna. Nos primeiros ensaios, usou luzes coloridas para criar a atmosfera de festa, mas, insatisfeito com o resultado, resolveu eliminá-las e substituí-las somente pelo azul e pelo branco. Todeschini acrescenta que o diretor trabalhava, quase sempre, com o quente (para gerar atmosferas de pôr do sol, aurora) e com o frio (para gerar atmosferas dramáticas e noturnas).

No que se refere à velocidade da luz, o diretor optava pela lenta. Privilegiava as passagens delicadas da aurora para o meio-dia; da tarde para o anoitecer; e do anoitecer para a noite. Tinha, também, predileção especial por atmosferas que mostrassem uma sutil entrada do sol pela janela -- sentia-se atraído pela ideia de iluminação que entrasse por uma fresta e envolvesse, pouco a pouco, o ambiente.

E, ao lado das luzes, encontra-se a música, elemento que assume, também, grande importância nos espetáculos strehlerianos. Vale mencionar que a experiência musical de Strehler iniciou na infância -- uma vez que o diretor vivia em um ambiente artístico: sua mãe era violonista e seu avô tocava corneta e era empresário do Teatro Verdi, de Trieste, e proprietário de duas salas de cinema -- e o acompanhou durante todo seu percurso artístico e criativo. Ele mesmo admite ter sido a música o início de tudo, a gênese de sua "veia artística" no teatro: "a música é o tecido da minha infância, da minha vida, e, até mesmo, do meu amor e do meu conhecimento teatral 14" (STREHLER, 1997, p.36). De fato, ela não era somente um dos elementos essenciais dos seus espetáculos, mas permeava todos eles de forma decisiva, fazendo-se presente tanto como som (trilha sonora), quanto como elemento de ostensão na enunciação dos atores. No primeiro caso, a música era inserida na encenação como personagem, muitas vezes, principal. Ela "recitava" e "atuava" nos momentos-chave da cena. Seu efeito era, metaforicamente, como os "sons" de Ariel em La Tempesta, os quais eram capazes de criar ambientes, hipnotizar, despertar, revelar, expressar, enfim, viver no espetáculo como personagem mágico, que age, gerando vida na encenação. Em Re Lear, por exemplo, Strehler utilizou a música como marcador dos momentos mais dolorosos do Rei, como indicadora de seu sofrimento e de sua insanidade.

No segundo caso, ela servia como base rítmica para os versos do texto. O diretor se preocupava extremamente com a "musicalidade" do texto dramático no palco. Tanto que, como anteriormente mencionado, escolhia tradutores - poetas para trabalhar na tradução dos textos estrangeiros. Ritmo e atuação eram, para Strehler, dois polos dialéticos no palco. Deveriam caminhar juntos no desempenho do ator.

Talvez essa seja a razão pela qual o diretor dirigia seus atores na recitação de um texto dramático como se fosse condutor de orquestra. Cada linha era trabalhada como se fosse extraída de uma partitura musical. Os atores reconheciam essa característica musical de Strehler e adquiriam, com ele, um modo particularmente rítmico-musical de enunciar seus papéis.

Essa sensibilidade especial em relação à música fazia com que o diretor tivesse um modo particular de escolhê-la ou criá-la para suas encenações. O músico Fiorenzo Carpi (1997) conta que, muitas vezes, Strehler precisava ouvir a música para pensar na construção de determinada cena. Isso aconteceu, por exemplo, na preparação da última cena de Il gioco dei pontenti ${ }^{15}$. Strehler esperou que Carpi terminasse a composição musical para então construir a cena.

Algo parecido ocorreu com Simon Boccanegra, ópera lírica encenada no Teatro Alla Scala, em 1971. A coreógrafa Marisa Flash (1997) conta que Strehler e Frigerio só conseguiram pensar no ambiente do último ato (um navio, cujas velas faziam-no subir e descer), no qual Simon morreria, ao ouvir a música da cena.

Nesses casos, era como se a música servisse de inspiração para a elaboração da atmosfera cênica. Outras vezes, a inspiração musical de Strehler acontecia durante os ensaios. As ideias surgiam naquele "doloroso" percurso de construção artística e criativa do espetáculo. E, como acontecia com a verbalização das ideias na construção dos outros elementos, Strehler não conseguia "explicar" aos músicos o que queria. Então, não sugeria ideias, mas atmosferas musicais. E Carpi, que acompanhava quase todos os ensaios no palco, entendia as sugestões de Strehler e conseguia criar o ambiente musical que o diretor buscava.

A sensibilidade musical de Strehler -- sua noção rítmica, ou, "seu ouvido sonoro" -- era, a meu ver, uma das características que o conduziam, quase instintivamente, a realizar espetáculos harmoniosos. Sua principal exigência era que todos os elementos de suas montagens se comunicassem, de modo que o público, ao assisti-las, se deparasse com algo sólido, coeso, simétrico. Para Spinatelli (1997), essa preocupação extrema de

14 [...] La musica è il tessuto della mia infanzia, della mia vita, e anche del mio amoré e della mia conoscenza teatrali. 15 Produção teatral em que Strehler reuniu as três partes de Henrique VI, de Shakespeare. 
Strehler em criar uma comunicação coesa entre os elementos do espetáculo fazia com que o público sentisse que havia algo na encenação que unia todos os seus elementos e os colocava em um grande conjunto harmonioso. Era como se uma "linha transparente" costurasse tudo com precisão.

Após sistematizar o texto e os elementos visuais do espetáculo, Strehler começava a trabalhar com os atores e com a equipe técnica para a construção concreta da produção. A primeira etapa dos ensaios, que Strehler chama de "prove al tavolino" [ensaio à mesa], consistia na leitura dramática e estudo do texto. Era a fase crucial para que os atores, sob a coordenação do diretor, encontrassem o melhor ritmo e a melhor entonação para a recitação de seus papéis.

Além disso, era o momento em que Strehler interpretava e estudava o texto junto aos atores, construindo com eles as características físicas e psicológicas de cada personagem. Segundo o ator Gianfranco Mauri (1997), "Strehler tem um belo costume: para cada personagem escreve uma ficha e a lê para nós, atores; são muito boas essas fichas, descrevem as características dos personagens, as suas motivações, seus defeitos, etc. ${ }^{16}$ " (p. 51). Fruto de seu trabalho de interpretação textual que, como mencionado anteriormente, era feito de modo reflexivo e "ingênuo".

Nessa etapa do processo, os atores eram convidados a expressar sua inventividade, construindo seus próprios papéis e sua própria forma de recitação. $\mathrm{O}$ diretor procurava não interferir diretamente no processo criativo dos atores, pois sabia que eles encontrariam sugestões interessantes e que ele teria bons resultados, mas ajudava-os com sugestões, opiniões, explicações. Estava ciente de que era necessário conceder aos atores o papel central de agentes ativos na construção do espetáculo, não só no âmbito da criatividade, mas também nas questões críticas, reflexivas do texto e de cada elemento constitutivo do espetáculo.

Essa primeira fase de preparação era imersa em uma atmosfera de constante criação artística: uma cadeia infinita de ideias que crescia a cada comentário, a cada insight interpretativo, a cada percepção, enfim, a cada inspiração.

Após os ensaios à mesa, Strehler conduzia o seu "núcleo criativo" para o palco, a fim de movimentá-lo no espaço cênico, para começar a criar condições concretas para a encenação. Nessa segunda fase de criação, definida pelo diretor como Prove in piedi [ensaios em pé], os atores se reuniam no palco no intuito de colocar em prática o que foi construído no ensaio à mesa. Era o momento em que eles buscavam adequar a construção de seu personagem com os elementos visuais da montagem.

No palco, eles conseguiam sentir a atmosfera da encenação de forma mais concreta, através do ambiente (ainda que provisório) criado pela equipe técnica. Tudo ainda estava em processo de construção. Nada era definitivo e o espaço cênico ainda estava aberto para a criação dos personagens, que acontecia por meio de discussões, reflexões, interpretações e, sobretudo, "liberdade de expressão artística". Ali, naquela cena em construção, Strehler continuava a estimular a inventividade de seus atores e eles conseguiam, aos poucos, dar vida concreta a seus papéis.

Strehler revela que o processo de construção da identidade de um personagem era extremamente monótono, pois consistia em uma cadeia infinita de repetições. Por vezes, uma única linha do texto ou um único gesto eram repetidos centenas de vezes. No percurso dessa fase de construção concreta dos papéis residia o desafio das possíveis correções sugeridas por Strehler. O fato é que, uma vez cristalizados na mente e nos gestos dos atores, os papéis passavam a ter vida e era difícil para o elenco voltar atrás e fazê-los de outro modo. No entanto, era nesse trajeto doloroso, repleto de desafios, que os elementos provisórios da montagem se tornavam, aos poucos, definitivos. Os ensaios no palco seguiam até às vésperas da primeira encenação e eram abertos aos grupos de alunos, profissionais do teatro e amigos. Dessa forma, Strehler, com seu espírito didático acerca do teatro, oportunizava ao pequeno público uma "aula" de encenação.

Geralmente, o diretor começava os ensaios com sua equipe às 16:00 e seguia até meia-noite. O modo particular de Strehler na condução e preparação dos espetáculos explica a razão pela qual o diretor procurava trabalhar repetidamente com as mesmas equipes técnica e artística: todos os membros já estavam acostumados ao seu ritmo, conheciam suas técnicas e suas estratégias e, apesar de enfrentarem desafios e serem expostos a momentos de esgotamento, confiavam em Strehler e sabiam que, com ele, alcançariam bons resultados.

Certamente, o desejo de Strehler em ver um espetáculo tecnicamente perfeito o conduzia a agir constantemente no limite de suas emoções. Tanto que, durante os ensaios, a sua relação com os atores sustentava-se no limiar entre o amor e o ódio. Porém, no final, todos compreendiam que o cansaço físico e psicológico na preparação de um personagem era parte do universo teatral (sobretudo do universo dos espetáculos dirigidos por

$16 \quad$ Strehler ha un'abitudine bellissima: di ogni personaggio fa una scheda scritta, e la legge a noi attori; sono bellissime quelle schede, descrivono i caratteri dei personaggi, le loro motivazioni, i loro diffetti, ecc. 
Strehler). No fim, as dificuldades eram superadas e os resultados eram quase sempre gratificantes. E, no final de cada encenação, Strehler reconhecia o trabalho feito pelos atores e tornava pública sua satisfação por meio de cartas e/ou até pessoalmente.

Em depoimento, enfim, o diretor revela a sua própria intensidade física e emocional ao preparar um espetáculo, sobretudo uma ópera, e reitera que se trata de um caminho que o conduz ao bom trabalho:

Se tenho que cuidar da direção de uma ópera lírica' estudo a música como se eu fosse tocála e faço os atores repetirem as falas cem vezes: Ando quilômetros entre palco e plateia para corrigir um gesto ou sugerir uma entonação diferente ou para controlar as luzes. Sim' senhor' infernizo os atores' os técnicos' os cenógrafos e todos aqueles que trabalham comigo 'Mas' me infernizo também. Grito' me agito' me torno cruel' exijo o impossivel' Infernizo tudo e todos até que não se chegue aos resultados que me parecem certos ou aceitáveis. Confesso que se alguém se distrai' passo a odiá-lo verdadeiramente [...] mas tudo isso' para mim' significa somente fazer bom trabalho. Não são manias e não tem nada a ver com perfeccionismo. ${ }^{17}$ (1997, p.196)

Essa exigência quase desumana de Strehler para com sua equipe e, naturalmente, com ele mesmo, para que os elementos constitutivos de suas montagens fizessem parte de um polissistema coeso e coerente era parte indispensável e imutável de sua metodologia artística e intelectual e que o conduzia, junto à sua equipe, a resu tados quase sempre satisfatórios.

Enfim, diante dos fatos relatados no decurso deste trabalho, poderia dizer que o diretor italiano não se destaca somente pela exigência severa e, como ele mesmo diz, "infernal", com a qual lida com as montagens e com os agentes neles envolvidos. Strehler destaca-se também pela sua capacidade inventiva, inovadora e politicamente crítica para conceber as encenações que, a meu ver, se colocam em um patamar muito mais alto de relevância artística e intelectual, do que o temperamento intolerante com o qual ele lida com o percurso preparatório das encenações.

E esse potencial criativo de Strehler em produzir e dirigir os espetáculos se deve, em primeiro lugar, ao meio artístico no qual cresceu. Seu ambiente familiar, cercado pela música, contribuiu de modo decisivo para despertar, desde cedo, seu olhar inquieto para as artes, sobretudo, para o teatro. Em segundo lugar, à convivência com os amigos e companheiros politicamente conscientes, que se preocupavam -- em uma época permeada pelas incertezas do pós-guerra -- em utilizar o teatro como canal de manifestos e de expressão política e como escola de civilidade, quando grande parte da população italiana ainda era analfabeta.

Esses fatores desempenharam papel decisivo no itinerário artístico e intelectual do diretor, contribuindo para que ele utilizasse os polos (ratio e emotio) de seu trabalho artístico de modo eficaz, envolvendo-se em constante busca por signos que constituíssem crítica e artisticamente suas encenações em todos os elementos constitutivos de sua arquitetura. Estava ciente de que um espetáculo se faz dia após dia, em uma gênese constante, contínua e coletiva. Seu magma criativo se transformava a cada nova leitura do texto, a cada colóquio com suas equipes técnica e artística, a cada ensaio -- o qual proporcionava, a partir da expressão de criatividade dos atores, um território vasto de inventividade -- enfim, a cada nova ideia ou insight artístico que surgia no percurso de constituição do espetáculo.

Como resultado de todos esses elementos, suas produções, em sua grande maioria, se enquadram em uma esfera artística de alta qualidade estética -- uma vez que há zelo, precisão e dedicação na constituição de cada um de seus elementos -- e cultural, pois mantêm, quase sempre, uma relação dialética com a política e a sociedade e buscam desempenhar uma função civil que vai além do entretenimento.

\footnotetext{
17 Se devo curare la regia di un'opera lirica mi studio la musica come se dovessi suonarla e faccio ripetere la stessa battuta anche cento volte, copro chilometri fra platea e palcoscenico, sempre su e giù, per correggere un gesto, per suggerire una diversa intonazione o per controllare una luce. Sissignori, rompo le scatole agli attori, ai macchinisti, agli scenografi, a chiunque sta lavorando con me. Ma le rompo anche a me stesso. Urlo, mi agito, divento crudele, pretendo l'impossibile. Faccio l'inferno fino a che non si arriva al risultato che mi pare giusto e accettabile. [...] Confesso che se scopro qualcuno distratto io lo odio, veramente. [...] però tutto questo, per me, significa solo fare un buon lavoro. Non sono manie, e non c'entra con il perfezionismo.
} 


\section{Referências}

CARPI, Fiorenzo. Depoimento. In: STAMPALIA, Giancarlo. Strehler dirige: Le fasi di un allestimento e l’impulso musicale nel teatro. Milano: Marsilio, 1997. p.214.

CASIRAGHI, Stella. Lettere sul teatro. Milão: Rosellina Archinto, 2000.

FLASH, Marisa. [Depoimento]. In: STAMPALIA, Giancarlo. Strehler dirige: Le fasi di un allestimento e l'impulso musicale nel teatro. Milano: Marsilio, 1997. p.53.

FRIGERIO, Enzo. [Depoimento]. In: STAMPALIA, Giancarlo. Strehler dirige: Le fasi di un allestimento e l’impulso musicale nel teatro.Milano: Marsilio, 1997. p.84

MAURI, Gianfranco. Depoimento. In: STAMPALIA, Giancarlo. Strehler dirige: Le fasi di un allestimento e l'impulso musicale nel teatro. Milano: Marsilio, 1997. p. 51.

MODICA, Gerardo. Depoimento. In: STAMPALIA, Giancarlo. Strehler dirige: Le fasi di un allestimento e l’impulso musicale nel teatro. Milano: Marsilio, 1997. p.78.

PAGLIARO, Walter. [Depoimento]. In: STAMPALIA, Giancarlo. Strehler dirige: Le fasi di un allestimento e l'impulso musicale nel teatro. Milano: Marsilio, 1997. p.70-71.

SPINATELLI, Luisa. [Depoimento]. In: STAMPALIA, Giancarlo. Strehler dirige: Le fasi di un allestimento e l'impulso musicale nel teatro. Milano: Marsilio, 1997. p.73-79.

STREHLER, Giorgio. [Depoimento]. In: STAMPALIA, Giancarlo. Strehler dirige: Le fasi di un allestimento e l'impulso musicale nel teatro. Milano: Marsilio, 1997.

TODESCHINI, Adriano. [Depoimento]. In: STAMPALIA, Giancarlo. Strehler dirige: Le fasi di un allestimento e l'impulso musicale nel teatro. Milano: Marsilio, 1997. p.137-138.

WILSON, Robert. Prefazione. In: STAMPALIA, Giancarlo. Strehler dirige: Le fasi di un allestimento e l'impulso musicale nel teatro. Milano: Marsilio, 1997. p. 11-16. 